\title{
The Importance of Investments in Human Capital in the Process of Innovation in Production
}

\author{
Fedor Mikhailov \\ dept. of human recourse management \\ Kazan (Volga region) Federal University \\ Kazan, Russia \\ mifb@ rambler.ru
}

\author{
Dmitrii Miasnikov \\ dept. of human recourse management \\ Kazan (Volga region) Federal University \\ Kazan, Russia \\ dmitriymyasnikov@mail.ru
}

\begin{abstract}
Modern researches of dynamic processes in the sphere of economy show that in the conditions of globalization noticeable acceleration of diffusion of innovation is observed. This is due to the fact that ensuring the economic sustainability of organizations is largely associated with the effective introduction of innovations in technological processes. However, at the stage of recovery from the economic crisis, enterprises are experiencing significant financial difficulties. Because of this, attempts are made to local inclusion of new technology in existing technical systems. This saves financial resources, but also creates great difficulties in the operation of such hybrid systems.

The purpose of the study is to find optimal solutions for the development of investment programs for the modernization of production and the achievement of effective parameters for the operation of hybrid technical systems, including traditional and innovative types of equipment.

In the course of the study, simulation modeling with the use of economic and mathematical methods was used, allowing to reach the methodology of optimizing the ratio of investments in the development of a hybrid production system and human capital of the organization's personnel.

Practice has shown that the increase in investment in the development of human capital of the organization's personnel can significantly reduce the overall cost of operation of the technical system and improve its performance.
\end{abstract}

Keywords: globalization, diffusion of innovation, investments, hybrid technical systems, development of production, human fund, efficiency

\section{INTRODUCTION}

Innovation, as a key factor of economic growth, has been in the center of the world science attention since the first third of the twentieth century. The emergence and continuous development of global information infrastructure has significantly accelerated the diffusion processes and management innovations. In real production, the introduction of innovative technical systems, as a rule, leads to the need for significant changes in the personnel management system. It is known from the economic theory that very often the introduction of technical innovations in the field of production occurs in the phase of the recovery from the crisis of the cycle of economic conditions. In this case, innovation is seen as a driver of economic growth and as a decisive factor in the development of the organization.[1] This is the technology change phase in the real business cycle Figure 1.

Picture one shows the phase of implementation of hybrid technical systems (D, P, E, R), the creation of which is caused by a sharp fall in the profitability of traditional technologies $(\mathrm{S})$, due to the diffusion of innovations that define the further development of the industry (B). The segment of the business cycle model (D-E) lifting area characterizes the achievement of the necessary effect of using hybrid technologies to reach the trajectory of sustainable economic growth.

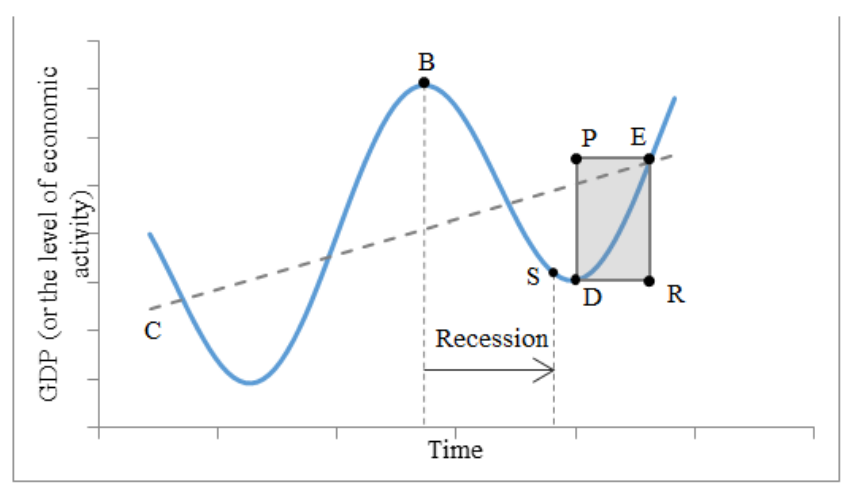

Fig. 1. Phase of implementation of hybrid technical system in real business cycle.[2]

B - innovative shock;

$\mathrm{S}$ - critically low profitability of traditional technologies;

D - introduction of hybrid technical system;

$\mathrm{D}, \mathrm{P}, \mathrm{E}, \mathrm{R}$ - phase of introduction, mastering and achievement of marginal efficiency of hybrid technical system in competitive market environment;

D-E - increase of efficiency of new technology.

\section{LITERATURE REVIEW}

This article used the literature on the theory of overlapping generations of population and overlapping generations of fixed capital, namely the macroeconomic model OLG (P. Diamond ) [3], which was the subject of a wide discussion of famous scientists, in particular, D. Romer [4], O. Blanchard [5], D. Acemoglu [6]. And the Fixed Capital Generation (FCG) model developed in 2016-V. I. Maevsky, S. Yu. Malkov, A. A. Rubinstein [7], which examines the macroeconomic patterns of overlapping generations of technology. The paper also investigated the priorities of advanced economic development in the conditions of changing technological structures in the foresight methodology, considered in the works of S. Yu. Glazyev [8]. The study of these theories showed that the problem of overlapping generations of technology has not yet been studied in microeconomic theory in relation to the 
real processes of introduction of combined technical systems of production, which became the subject of our study.

\section{METHOD OF RESEARCH}

The main reason, which motivates the organizations to modernize technical systems is the critical reduction in the profitability of traditional technologies due to the emergence of innovations in the competitive environment that form different production conditions. However, during the recession, organizations that were not at the forefront of innovation technologies are experiencing significant financial difficulties due to the fall in profitability of their products. In such situation, the management of the organization is forced to seek compromise solutions to the problem within the framework of the anti-crisis strategy.[9] The purpose of the solutions is to find a combination of traditional system, operating in the organization, and innovative technology, which allows to ensure the release of new demanded products in the market. As a result, a variety of hybrid technical systems are formed, in which new and traditional techniques are integrated. Such technologies are common for the recession of the economic situation in the business cycle.[10] The establishment of such technologies creates conditions for overcoming the crisis in the enterprise's development by transition to production, demanded in the market of products, and to accumulate the necessary resources for radical updating of the technical system. [11]

The significant financial difficulties, experienced by the organization, encourages its management to minimize the expenses of production. Highly qualified specialists with extensive experience in traditional maintenance are often involved in servicing hybrid technical systems. Thus, the organization seeks to save money for the development of personnel, believing that experienced specialists are able to master the management of new equipment independently.[12]

In the meantime, as the practice shows, previous experience in servicing traditional equipment is not able to compensate the lack of new knowledge that allows to work effectively with new equipment. In such situation, the reduction of investment for the development of personnel seems to be a strategically risky solution, because it can only give a short-term effect at the initial stages of development of combined technical systems, but in the future it is accompanied by a large risk of a significant decrease in production efficiency due to the increasing number of machine failures, poor repairing quality and increasing downtime.[13]

\section{RESULTS}

Figure 2 shows the simulation model of the process of mastering a combined technical system in the conditions of limited investments to the human capital.

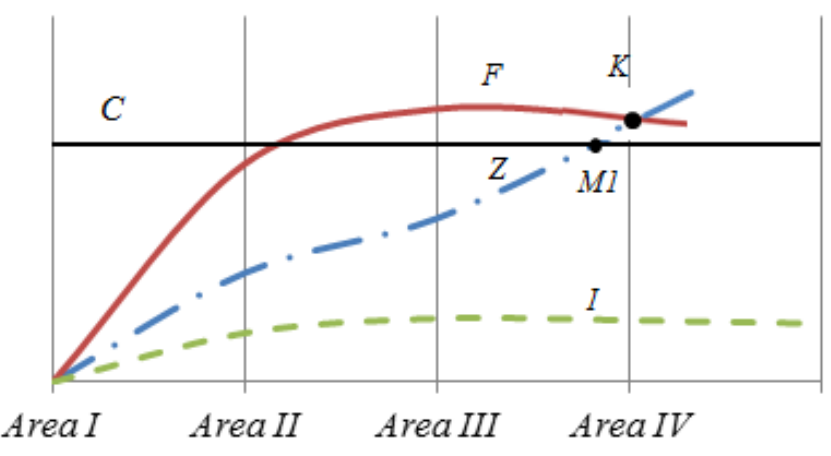

Fig. 2. Simulation model of the dynamic of production efficiency under the influence of changes in maintenance costs and investments in human capital (Compiled by the author on the basis of the study)

\section{Z-maintenance and repair costs,}

\section{F-Production efficiency,}

I- Investment in human capital,

C-level of maximum permissible costs,

M1- point, characterizing the maximum permissible level of operating costs of equipment under which sufficient profitability of production is ensured,

$\mathrm{K}$ - production costs are not compatible with the criteria of efficient use of new equipment.

Area I represents a situation of implementation of the technical system. It is characterized by low operating modes of the technical system. In these conditions, the equipment can operate fairly stable, and the personnel can still provide the necessary stability of its work.

In Area II, the equipment is taken to the design mode of operation. It is designed to increase its efficiency, but the maintenance and repair costs of the technical system are increased due to unplanned downtime and failures. Staff begin to experience difficulties in servicing new equipment due to lack of knowledge. The last thing begins to affect negatively to the production and stability of the technical system.

In Area III, production efficiency is reduced as a result of increased maintenance costs. They begin to exceed the maximum permissible norms, which adversely affects the profitability of production. This situation is due to the increase in the duration of the equipment stops, the failure of key units. The last thing is due to the lack of necessary knowledge and competence of the employees required for timely adjustment and repair of new equipment. The management of the companies tries to stimulate the workers for ensuring the sustainable work of the equipment, involving them to do extra hours, which leads to a significant increase in the intensity of labor of the staff, but does not contribute much to improve the quality of repairing and adjustment work.

Area IV is characterized by an increase in unfavorable trends in the growth of production costs and a decrease in its efficiency. Moreover, investment in human capital does not increase, and may even decline, owing to lower profitability of production and a noticeable decline in financial resources due to a fall in profits. 
In order to solve problems with the operation of the technical system, a group of experienced engineers are often identified, who are responsible for maintaining the stable operation of the technical system. In some cases, this allows to stabilize the situation, but, as a rule, a cardinal solution to the problems of machine health is not achieved. In the future, low-budget retraining programs are initiated for all staff who is engaged in the maintenance of the new equipment. In this case, as practice shows, an additional instruction is mainly offered in the form of training on servicing local segments of the technical system and introductory safety courses. In the meantime, special surveys show that employees need an intensive and advanced training allowing them to fully master the new knowledge that determines the effectiveness of functioning of innovative technology.

Such training program should be seen in the strategic context of the organization's activities, the aim of which is to bridge the gap between what employees know and can do and what they need to know in order to carry out their work in accordance with the requirements of effective operation of new equipment.

It is important to note that in modern economic theory, several models are considered, in which the effect of overlapping generations of the population in economic systems (OLG) and overlapping generations of fixed capital (FCG) appear.

At the same time, as special studies show, in the OLG model accumulated knowledge is sufficient to support the reproduction of economic activities, but the FCG model requires new ideas for coordinating the level of knowledge in the use of industries based on the closure of generations of fixed capital.

There is the reason to believe that such ideas include an approach based on the advanced rate of investment in human capital in the introduction of combined technical systems based on the practice model of overlapping generations of fixed capital (FCG).

It is a question of intensive training of the staff for mastering of technical innovations, which allows to considerably increase efficiency of implementation of innovative programs (figure 3). This figure shows a simulation model of the dynamics of production efficiency change depending on the ratio of production costs and investments in the company's human capital.[16]

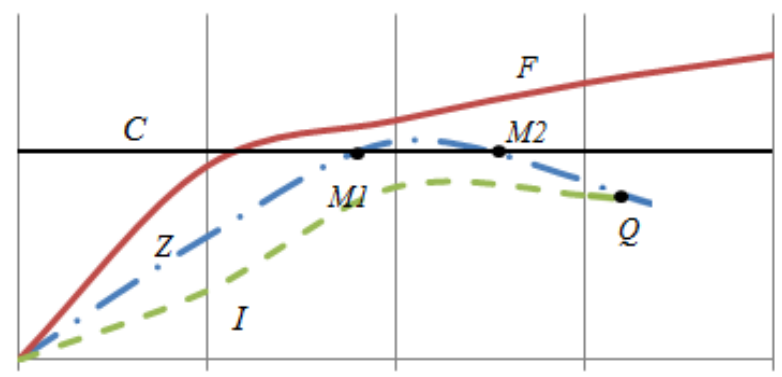

\section{AreaI AreaII AreaIII AreaIV}

Fig. 3. Economic-mathematical model of expenses changes for the production and investments into the company's human capital while the introduction of hybrid technical systems (b. Compiled by the author on the basis of the study)

Q - the point of optimization of the cost for introduction and development of the innovation system;
M1 - the point, characterizes the maximum-permissible level of the cost for the operation of the equipment in terms of profitability of production;

M2 - is the point of exit from the zone of the maximumpermissible level of costs for the operation of equipment, transition to the field of sustainable profitability of production.

Area I describes the implementation of a structurally close technical system, which is considered in the model in Figure 2. In this case, the introduction of equipment was also accompanied by modular training of employees. In this case, production costs began to grow at the same rate as in the case shown in Figure 1.

Area II is characterized by a higher rate of production costs due to the desire of management to bring the equipment to the design capacity more quickly. However, the understanding of the fact of the objective complexity of quality maintenance of equipment without proper preparation contributed to the decision of a significant increase in investment in the human resources of the organization, most of which was invested in training personnel.

Area III is characterized by a decrease in production efficiency due to the increase in the cost of ensuring the operability of the technical system, which staff have not yet mastered to the proper extent. This requires additional investment in staff development, which significantly increases the total cost.

Area IV - this area is characterized by a steady increase in production efficiency, which is achieved by increasing the level of maintenance of new equipment and optimal synchronization with existing systems within the framework of the organization of hybrid production. Thus, as a result of the increased investment in human capital, operational costs are reduced by reducing accidents and failures in the operation of the technical system.

\section{DISCUSSION}

There is the reason to believe that an increase in the share of investments in human capital can not only compensate for the increase in the cost of ensuring the operability of the technical system, but also increase its productivity.

Thus, additional investments aimed at development of human capital of the organization's personnel, in the conditions of modernization of the technical system allow to increase its efficiency significantly.

The development of the staff in this situation is a critical factor in the effective implementation of the strategy of innovation development of the company, including especially implemented in the operating conditions of technical systems created on the basis of overlapping generations of the main capital.

\section{CONCLUSION}

In economic theory, the Orthodox model of OLG overlapping population models, built by the American economist, Nobel prize winner (2010) P. Diamond, is widely known. Based on the concept of this model, the creative team led by academician V. I. Maevsky developed a model of overlapping generations of fixed capital FCG, which at the macroeconomic level shows some regularities in the circulation and reproduction of capital in the conditions of 
[3] P. A. Diamond, "National Debt in Neoclassical Growth Model," American Economic Review, vol. 5, no. 5, 1965, pp. 1126-1150.

application of different generations of technology in real production. Essentially, FCG-type models in the economic literature still remain outside the economic mainstream. In our study, we consider one of the prevailing options for overlapping different generations of technology at the microeconomic level in relation to real situations of domestic production at the stage of the latter's recovery from the crisis within the traditional model of the business cycle. This is an attempt by organizations to reach a competitive level of production under severe financial constraints. This circumstance makes it necessary to combine traditional technical systems and new (innovative) technology. Such situations have not been properly understood in microeconomic theory and have been little studied in the world economic literature of recent years. The problem is to integrate knowledge of the theories of production organization, innovation management and human resource management. The formation of technical systems based on overlapping generations of fixed capital is a real fact of basic production. For the effective use of such technical systems, special forms of human resource management are necessary, based on special programs for personnel development, their adaptation, and the formation of teams that include employees of overlapping generations with knowledge of the effective use of traditional and new technology. Modeling the situation of using combined technical systems, including overlapping generations of technology and the impact on the effectiveness of their use of factors on the side of human activity, formed the substantive basis of this article.

\section{REFERENCES}

[1] P. Davidsson and B. Honig, "The role of social and human capital among nascent entrepreneurs," Journal of business venturing, vol. 18 , iss. 3, 2003, pp. 301-331.

[2] N. A. Zaitseva, M. Y. Efremova, A. A. Iarionova, and O. N. Kostryukova, "Development of anti-crisis strategies of development of hospitality industry companies on the basis of formation of competitive HR potential," Contributions to economics, no. 9783319606958,2017 , pp. 505-513.
[4] D. Romer, Infinite-Horizon and Overlapping-Generations Models. Advanced Macroeconomics, $3^{\text {rd }}$ ed., N.Y.: McGraw Hill, 2006, pp. 47-97.

[5] O. J. Blanchard and S. Fisher, The Overlapping Generations Model, Lectures on Macroeconomics, Cambridge: MIT Press, 1989, pp. 91152.

[6] D. Acemoglu, Growth with Overlapping Generations. Introduction to Modern Economic Growth, Princeton University Press, 2008, pp. 327-358.

[7] V. I. Mayevsky, S. Yu. Malkov, and A. A. Rubinstein, "Theory of overlapping generations of fixed capital," Vestnik of the Russian academy of sciences, vol. 86, no. 1, 2016, pp. 56-65.

[8] S. Yu. Glazyev, "Priorities of advanced development of the Russian economy in the conditions of change of technological ways," Economic revival of Russia, vol. 2 (60), 2019, pp. 12-16.

[9] A. R. Toumashev, M. V. Toumasheva, E. R. Valeev, and D. A. Miasnikov, "Development of Russian economy in conditions of globalization and investment policy," Mediterranean Journal of Social Sciences, vol. 6, iss. 3, 2015, pp. 700-704.

[10] K. Gonchar and B. Kuznetsov, "How Import Integration Changes Firms," Decisions to Innovate, Annals of Regional Science, vol. 60, no. 3, 2018, pp. 501-528.

[11] N. Pain, E. Rusticelli, and V. Salins, "A Model-Based Analysis of the Effect of Increased Public Investment," National Institute Economic Review, vol. 244, 2018, pp.15-20.

[12] F. B. Mikhailov, O. V. Yurieva, and D. A. Miasnikov, "Strategies of the human capital development in conditions of accelerating diffusion of technical innovation under influence processes of globalization," Globalization and Its Socio-Economic Consequences, 18th International Scientific Conference, PTS I-VI, University of Zilina, Slovakia, 2018, pp. 2236-2243.

[13] D. K. Backus and P. J. Kehoe, "International real business cycles," Journal of political economy, vol. 100, iss. 4, 1992, pp. 745-775.

[14] F. B. Mikhailov, E. V. Fakhrutdinova, R. K. Yagudin, and M. A. Mefodeva, "Work optimization of the production staff when implementing technical innovations," Mediterranean Journal of Social Sciences, vol. 6 (1S3), 2015, pp. 86-90. 